\title{
Lung Colloid Adenocarcinoma
}

National Cancer Institute

\section{Source}

National Cancer Institute. Lung Colloid Adenocarcinoma. NCI Thesaurus. Code C45512.

A morphologic variant of lung adenocarcinoma characterized by the presence of mucin pools containing islands of well differentiated adenocarcinoma cells. 